\title{
La poética creativa de Fernando Alba
}

\author{
Jovino Martínez Sierra \\ Arquitecto / Doctor en Historia del Arte
}

RESUMEN

La poética creativa del artista asturiano Fernando Alba parte del entendimiento de la obra como proceso según una actitud de permanente pregunta hacia el espectador, ya sea como metáfora, símbolo o alegoría, mediante códigos implícitos.

$\mathrm{Su}$ actitud y modo de ver el mundo, la interrogación obsesiva, la denodada búsqueda de lo no conocido, las incursiones en las zonas limitrofes, la fascinación por la observación, son un medio de concienciación para el artista de la necesidad de preservar o rescatar las señas de identidad contemporáneas del hombre, de su tiempo y de su memoria.

\section{PALABRAS CLAVE}

Fernando, Alba, escultura, poética, creación.

\section{ABSTRACT}

The creative poetics of the asturian artist Fernando Alba depart from the understanding of the work as process according to an attitude of permanent question towards the spectator, already it is like metaphor, symbol or allegory, by means of implicit codes.

His attitude and way of seeing the world, the obsessive interrogation, the bold search of not known, the incursions in the bordering zones, the fascination for the observation, are a way of raising awareness for the artist of the need to preserve or rescue the contemporary signs of identity of the man, of his time and of his memory.

\section{KEYWORDS}

Fernando, Alba, sculpture, poetics, creation. 


\section{Nostalgia de la naturaleza}

El escultor Fernando Alba (La Folguerosa, 1944) cuenta con una trayectoria de más de cuarenta años de actividad creativa ininterrumpida tanto en Asturias como fuera de la región, cuyo trabajo ha contribuido a la renovación de la plástica asturiana desde 1960 hasta nuestros días, con relevantes intervenciones en espacios públicos. Galardonado con el premio nacional de escultura apenas cumplidos los veinte años, ha mantenido un posicionamiento artístico fruto de una continuada reflexión y profundas convicciones, cuya actitud permanente de búsqueda inconformista e inquieta actividad intelectual se manifiesta en su obra y personalidad, con una vida entregada al arte.

Si entendemos arte frente a objeto, como la representación conceptual que se añade a este, la obra del escultor asturiano Fernando Alba ha tenido una actitud contemporánea comprometida, reflexiva y vital, en un proceso continuo que plantea constantes interrogantes al espectador.

Los planteamientos escultóricos tienen la intención de trascender las limitaciones espaciales de la propia escultura, vinculando concepto, espacio y materiales a la memoria, al recuerdo y la existencia, conectados con la experiencia simbólica, finalmente interpretada por cada espectador.

La mirada interpretativa de la escultura se ve condicionada por muchos factores, esencialmente sociales, culturales y subjetivos. El posicionamiento del espectador repercutirá ineludiblemente sobre su visión de las obras. La mirada personal implica una libertad de pensamiento ante la escultura que se observa. El artista propone obras donde provoca la interpretación de imagen y conceptos de una manera propia y personal, incitado al deseo de esclarecer el significado más profundo de la obra, interpelando y estableciendo un cierto grado de seducción ante aquello que se observa.

La falta de respuesta de las vanguardias ante la crisis de pensamiento actual, ha hecho que Fernando Alba eligiera un camino personal como búsqueda de "esa verdad" perseguida en sus planteamientos, materializados en la investigación y expresión de los misterios que acompañan al ser humano en su existencia, manejados con una profunda poética según un entendimiento flexible y abierto de la contemporaneidad donde todo puede tener cabida en virtud de los matices conceptuales.
La nostalgia de la naturaleza vivida en la infancia y adolescencia ha estado presente en toda la trayectoria artística, de un modo más explícito o evocado con el uso frecuente de la madera. Siempre ha conjuntado necesidad y belleza haciéndonos ver que la superposición de ambas no es excluyente sino complementaria e indisociable: la belleza es necesaria y la utilidad es bella.

Los elementos naturales por excelencia para el artista son el árbol, la rama y la hoja. El árbol para Alba, es más idea que forma. El árbol ha sido utilizado en muchas fases como protagonista principal con la naturaleza como fondo. Ha sabido aunar los significados propios del tronco, las reflexiones y especulaciones intelectuales que contribuyen a potenciar su estructura y naturaleza. Tratado como objeto trabajado y no como objeto encontrado, siempre ha originado fricciones en su obra entre lo formal y lo simbólico, entre lo natural y lo elaborado, en la continua búsqueda de depuración del objeto. ${ }^{1}$

Alba trabajó con el árbol como materia prima en sus primeros troncos, de manera radical y mínima en las obra expuestas en la galería Tassili, vaciados y llevados al límite de su estructura y esencia en las expuestas en la galería Juan Gris en 1979, de manera virtual en la sombra de la palmera en Imagen real/Imagen virtual o trasmutado en un árbol de hormigón en la pieza del premio de Autopistas del Mediterráneo, en Tarragona.

Se podría afirmar que ha trabajado con una dualidad recurrente entre los elementos naturales y la materialidad abstracta de sus esculturas, interaccionando entre ambos. No hay nada que no esté ya inventado por la naturaleza. El material es en reiteradas ocasiones el fruto de un encuentro de la observación. El tronco de madera como obra escultórica ya casi dada por la naturaleza por la caída de un rayo, la piedra encontrada en un acantilado o las chapas viejas y oxidadas que tiene apiladas en el exterior de su taller son entendidas en sí mismos como objetos artísticos por la mera capacidad

RODRÍGUEZ, Ramón, Escultores Asturianos nacidos en las décadas 40 y 50, Consejería de Cultura en el Principado de Asturias, Oviedo, 1997 
de asumirlos ${ }^{2}$ como tales, para después transformarlos.

En las obras efímeras el concepto de paisaje aparece integrado con la propia obra e interactuando con ella. En Imagen real / Imagen virtual, Contenedores de tiempo, Círculo de Otoño o Sombras de Luz, no se podría llegar a entender la obra sin el medio. La imagen cambiante del medio se solapa con el concepto de instalación, realidad y enigma se funden y la obra adopta un carácter mágico.

De la materialidad del trabajo con troncos de sus primeros años a las intervenciones en la naturaleza de la delicadeza de Círculo de
Otoño (Fig. 1) y Octubre, a las alegorías planetarias de Sombras de Luz siempre existe una recurrente nostalgia y vuelta al elemento natural.

La naturaleza se trata en ocasiones de manera abstracta recogiendo la sombra de una palmera, o se interacciona con ella en el valle de Saliencia mediante un juego de opuestos o se geometriza en Círculo de Otoño mediante un gesto recogiendo las hojas y dejando una huella impresa artificial. La levedad del plano de hojas y líquenes flotando entronca directamente con las preocupaciones del land art, en cuanto a ese interés por las cualidades específicas del mate-

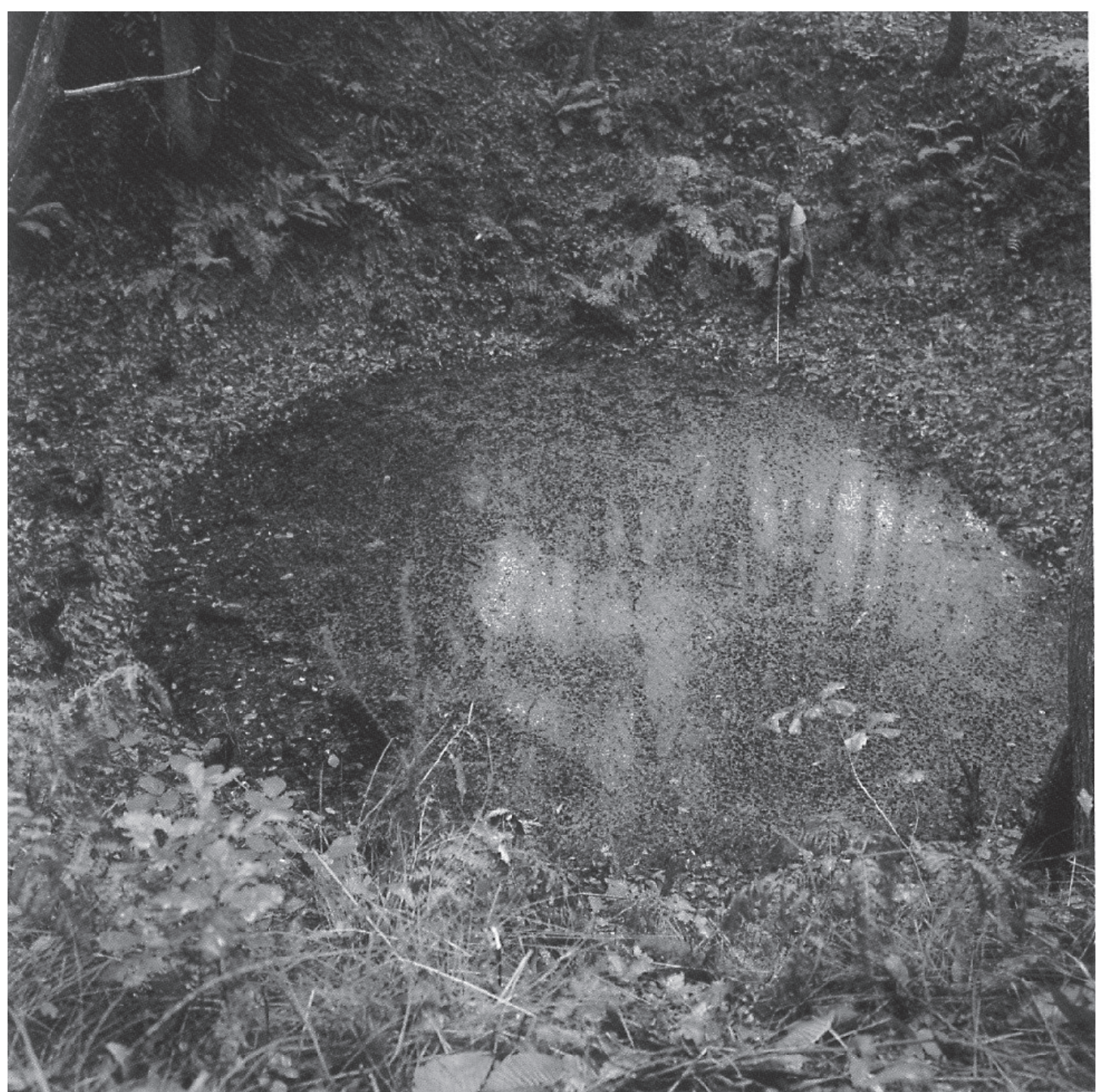

Fig. 1. Fernando Alba. Círculo de otoño. San Claudio. Oviedo. 2003

Esta asunción requiere un pensamiento y una reflexión en el tiempo para el artista. 
rial como su capacidad de respuesta ante la ley de la gravedad y el carácter biodegradable.

La obra enmarcada en un espacio natural de mayor potencia es la del valle de Saliencia en la que Alba realiza una operación de oposición mediante el uso de la geometría y de la materialización, en una obra que dialoga con el impresionante entorno natural a modo de huella impresa por el hombre. Lo orgánico y lo geométrico se relacionan en el plano formal: el medio es parte integrante de la propuesta plástica del artista.

La naturaleza representa en gran medida la nostalgia a la infancia pero también los valores perdidos del hombre en la crisis de pensamiento actual. Alba no es ajeno al pensamiento oteiziano del sentido de la obra de arte como concepto metafísico como servicio espiritual al hombre y a la sociedad.

En una de las estanterías del taller del artista descansa un espacio cóncavo, mágico y emocionante. Se trata de una estructura entretejida con pequeñas ramas. Podría ser la maqueta de una escultura abstracta, y sin embargo es el nido de un pájaro. La naturaleza imita al arte.

\section{Concepto del tiempo}

La obra de Alba se enlaza también con el concepto heideggeriano de temporalidad, entendido como un nivel profundo de representación, como una unidad que abarca pasado, presente y futuro, superando la vinculación al objeto artístico. Las obras contienen múltiples referencias al bosque, a lo sagrado, a la fiesta, a lo telúrico, a lo desconocido, y en definitiva, a nuestra propia condición y existencia frente a los misterios que nos rodean. ¿No fue esa la primera respuesta que intentó ya dar el hombre en las primeras representaciones artísticas?

El artista parte de la observación, el análisis y la intuición de la obra según un proceso de racionalización y por tanto no azaroso que concluye en la determinación de forma y espacio, transmutando esencias de tiempo y sensaciones poéticas. Contenedores de tiempos (Fig. 2) sintetiza el concepto de tiempo vinculado al espacio como contenedor y la fugacidad inherente como materia de pensamiento. Cuatro elementos interrelacionados e iguales dos a dos en su composición secuencial nos aproximan a tiempos detenidos, ligados en su

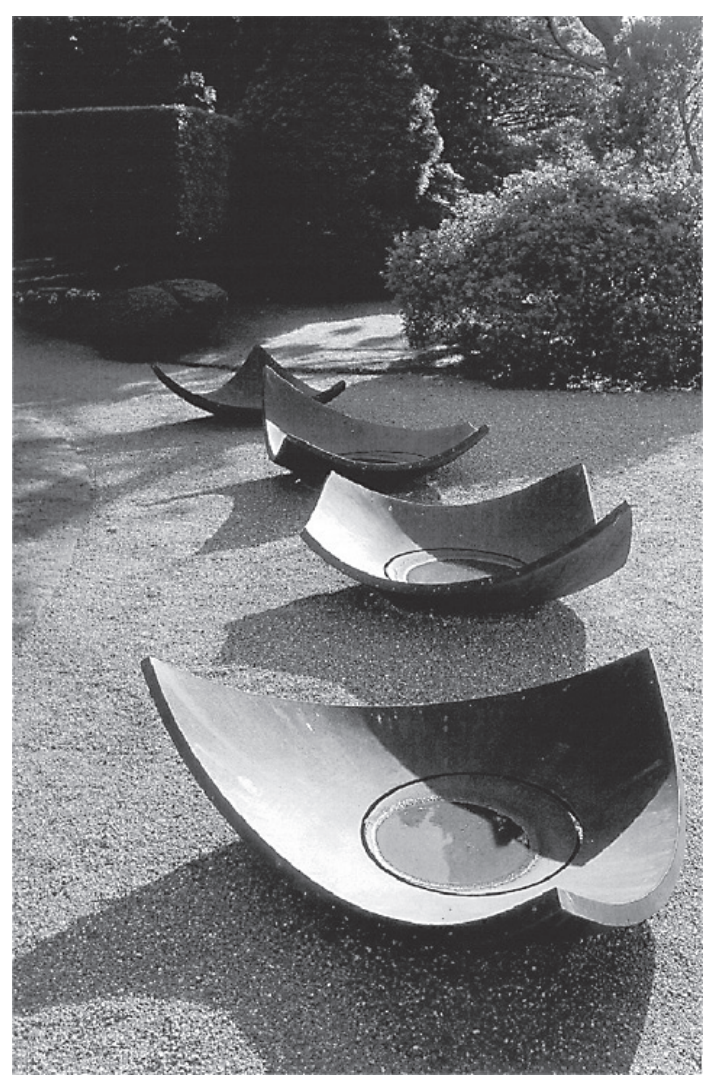

Fig. 2. Fernando Alba. Contenedores de tiempo. Museo Evaristo Valle. Gijón. 2003

discurso rítmico, sinuoso y dinámico a la idea de fugacidad. La formalización del concepto se apoya en unos elementos cóncavos que tienen la capacidad de contener sin retener, conceptualizando contradicciones del ser: plenitud y fragmentación, conviviendo en el mismo contenedor como partes indisociables de la naturaleza humana.

El material, acero, agua y hojas secas, vinculada a la misma esencia y origen de la vida y tan sensible a su discurrir a través del movimiento, de la evaporación, de la descomposición de las hojas y en definitiva, de la fugacidad del tiempo. En las obras convive lo concreto y lo abstracto enfrentados dialécticamente. Lo orgánico coexiste con lo geométrico, consiguiendo conjuntar un mundo de sensaciones y alegorías a la naturaleza de absoluta contemporaneidad. Organicismo y racionalidad, material y concepto, génesis y discurso, llevan a la obra de Alba a la frontera de lo mítico y a la confluencia de lo consciente y de lo imaginario.

El proyecto de las vanguardias se ha resquebrajado y en la actual crisis se impone una reformulación personal como punto de partida, 
es decir, construir una génesis personal de la conciencia y pensamiento contemporáneo.

Los aspectos autobiográficos conforman esa identidad adquiriendo una importancia capital, en esa posición inestable entre pasado y futuro donde la obra se redefine como proyecto vigente para nuevos espacios. Fernando Alba ha creado un universo personal como expresión de su propia individualidad y su tiempo, usando los instrumentos y el lenguaje contemporáneo pero sin adscribirse a ningún movimiento artístico.

Sus obras tienen una vocación de atemporalidad que abarca pasado, presente y futuro, alcanzando a mantenerlas en un estatus de contemporaneidad. Son esencias de tiempo y espacio en un sentido poético y metafísico, con el concepto de secuencia y proceso como determinantes en la materialización de su escultura.

\section{Volúmenes y espacios}

Decía Duchamp que "el gran problema" radicaba en "el acto de escoger". La obra de Alba es una transformación, permitiéndonos habitar en aquel hueco abierto para captar la realidad transformadora por la libertad creadora. ${ }^{3}$

Alba ha situado sus obras en un entorno urbano como en Sombras de Luz o geológico y paisajístico como la obra del valle de Saliencia y ha puesto en relación los elementos y las fuerzas del lugar creando espacios para las obras.

La experimentación con la escala ha adquirido enorme importancia ya que su aplicación a la obra afecta de manera total al recorrido que el espectador necesita para aproximarse a una escultura y al igual que el recorrido tiene una enorme importancia en la experiencia temporal, la escala se incorpora a la percepción general de manera fundamental en la secuencia perceptiva de acercamiento.

El tamaño impone un tiempo y una manera de aproximación con múltiples perspectivas cambiantes desde cada punto de vista. Podríamos hablar sobre una percepción cinematográfica de la obra y hasta una posible concepción de la misma como suma de multitud de fotogramas. En ocasiones para entender una obra necesitamos la suma de imágenes parciales e

\footnotetext{
MALLO, Avelino, "Intervalos de luz". La Nueva España,
} Oviedo, 22 de junio de 1999 incluso la necesidad de alejarnos para volver a tener una comprensión global. Esta capacidad cinestésica del cuerpo, nos habla de la captación de sensibilidades hacia el propio movimiento y su ubicación.

Es necesario resaltar como en las obras Alba destaca siempre lo "importante" frente a lo "secundario" despreciando lo "anecdótico" por prescindible. El escultor entiende cómo las preocupaciones formales, técnicas y materiales podrían constituir un riesgo si no se canalizan adecuadamente para debilitar el proyecto distrayéndolo hacia preocupaciones superficiales. Resulta frecuente la realización de una lectura secuencial de órdenes o capas de pensamiento que se traducen en una jerarquía conceptual en sus obras. Dicha secuencia se manifiesta de manera clara en Sombras de Luz en la lectura de espacios secuenciales, repeticiones o mecanismos que acentúan la intencionalidad de la escultura, llevando en algunas ocasiones a "la escultura fuera de la escultura" es decir, valorando el espacio y la relación de la obra con el espacio y el espectador con la misma intensidad y densidad que el de la propia obra.

El espacio para Alba, en la medida que es: ${ }^{4}$ "una lucha permanente" que representa una búsqueda de lo que rodea la existencia y por tanto es una respuesta personal a los interrogantes y preocupaciones del artista. El espacio es al tiempo mágico, telúrico, insondable, penetrante y poético.

\section{Disolución de los límites}

La obra del artista no se puede entender sin la conjugación de la formación y sensibilidad personal con los aspectos biográficos que le han acompañado. La disolución del espacio con vocación de infınitud, produce una cierta perplejidad inseparable de una reflexión del porqué de la obra de Alba. En el tratamiento de los límites de las obras, se encuentran los interrogantes que el artista formula constantemente. En la materialización de un pliegue, una sombra, un hueco, un borde volado, se encuentran las reflexiones y preguntas que Alba formula al espectador.

Alba recurre frecuentemente a esta expresión, en la medida que supone un combate, una pelea al borde del abismo, necesario para la creación. 
La geometría que subyace en la mayoría de las obras sirve de patrón organizador y estructurador de las mismas. No obstante las leyes de formación geométrica son llevadas un paso más allá en la sensible manipulación del gesto, del orificio o del pliegue hasta obtener un orden de libertad capaz de disolver los límites de la obra.

Podríamos afirmar que Alba maneja amplios grados de libertad combinados con una profunda y minuciosa reflexión en cualquiera de los gestos empleados. Al artista le interesan los límites de las cosas, en esa frontera donde las ideas empiezan a ser y dejan de serlo. En el pensamiento, en los límites, el escultor se siente cómodo más cerca de las intuiciones que de las certezas. Alba no busca lo permanente y lo estable sino seguir constantemente en la búsqueda y la intuición de lo no conocido.

El artista utiliza los materiales como recurso para acentuar los límites. Por ejemplo, el agua como material acotado y contenido (o imposible de contener) o utilizado como telón de fondo que transcurre en las profundidades, genera un plano perceptivo de inquietante evocación de significados ocultos.

El acto creador está más cerca de la imaginación que de la percepción. Alba se mueve en un tiempo lento, muy lento. Correr no es la solución. Necesita y se relaciona mucho mejor con la serenidad. Su naturaleza necesita un tiempo muy lento y lo manifiesta en un proceso creativo, reflexivo y pausado.

El límite como materia conceptual es un elemento esencial de trabajo para el artista en ese continuo plantear interrogantes sobre la existencia. Preguntas que son formuladas y dejan la respuesta al espectador y que por tanto insinúan formulaciones abiertas a la interpretación y sensibilidad personal.

Alba ha pasado de la experimentación de la masa o del vacío a manejar la escultura con materiales livianos: espejos, láminas de espesor mínimo, chapas de proporciones muy esbeltas, ejercicios de land art con hojas, etc. que refuerzan el concepto de levedad que tanto tiene que ver con los límites y que son una de las bases de sus preocupaciones intelectuales.

Su concepción existencial le lleva a planteamientos de reflexión sobre la temporalidad, la fugacidad y el devenir. Estos conceptos arrojan en su plástica una inquietante levedad de las formas que acaban en esa voluntad de flotar sobre el suelo o de elevar planos plegados lige- ramente. De este modo, los límites se disuelven y la materia importa cada vez menos atrapando la idea de la obra entre la poética formal y conceptual.

Quizá en la sociedad de la información que vivimos, la escultura desmaterializada, la "no escultura" se superpondrá en el futuro a cualquier soporte físico. De ahí la contemporaneidad de Fernando Alba: utilizando materiales y soportes tradicionales, nos sigue hablando de otro mundo, de su trascendencia, y en definitiva, de nuestra sociedad y de su tiempo.

\section{Energía telúrica}

Quizá uno de los mecanismos o resortes íntimos del creador son las representaciones o lecturas para el observador. La linealidad en las lecturas de los conceptos se hacen más evidentes en algunas piezas que en otras pero siempre está presente un misterioso juego de interrogantes a modo de constantes que subyacen tras las obras.

Las obras de Alba responden a problemas concretos pero también dan respuestas a preguntas o intereses del escultor acerca de los misterios que acompañan la existencia del ser humano. En este sentido destilan una potencia o energía procedente de la tierra ${ }^{5}$ en ese intento de despegarse de ella, a veces flotando como en Voces, Ecos, levedad del tiempo, otras plegándose como en Devenir, en ocasiones con oquedades o con abultamientos, en el caso de Silencio Orgánico (Fig. 3).

Una obra para llegar al final, tiene que pasar por muchas instancias y una de ellas, es localizar las fuerzas que no son visibles, que son producto no sólo de la inteligencia o de la cabeza o de la habilidad o la potencia física. Fuerzas que son más misteriosas pero necesarias. ${ }^{6}$ Además de poseer una concentración de fuerzas naturales, existe implícito el concepto de entropía, con el mismo valor que la presencia. Su tiempo es más el de la naturaleza y de los árboles. La degradación y la vejez están previstas de una manera anticipada, noble y conocida. Todo pa-

\footnotetext{
ALVAREZ MARTINEZ, María Soledad, "Fernando Alba (La Folguerosa. Salas. 1944)”. Artistas asturianos. Escultores, IX, Hércules Astur Ediciones, Oviedo, 2005, pp. 262-295

6 CHILLIDA, Susana, Elogio del Horizonte, Conversaciones con Eduardo Chillida, Ed. Destino, Barcelona, 2003
} 


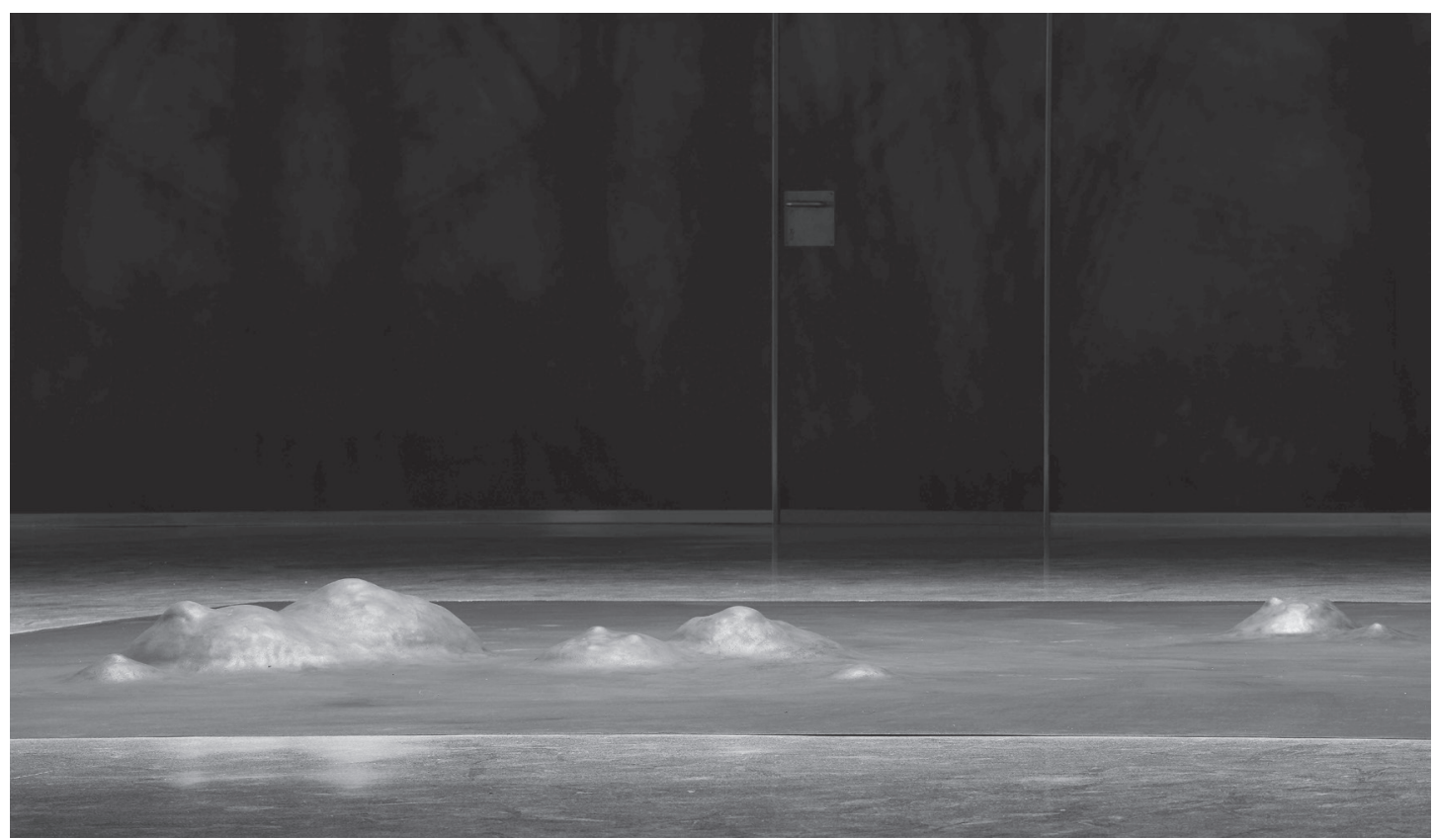

Fig. 3. Fernando Alba. Silencio orgánico. Centro de Salud Mieres Sur. 2008

rece emanar de la energía de la madre tierra en ese diálogo constante que Alba establece con el mundo natural: lo profundo e insondable que emana del misterio del ser y que parte de la propia naturaleza.

\section{La poética de la luz y la sombra}

La dimensión poética se inicia en la sugerencia ocultada en el misterio evocado, abriendo un abismo entre lo conocido y lo sugerido que nos recuerda, además de lo que sabemos y reconocemos, otras claves invisibles sin las cuales no podríamos completar el sentido de cada obra. Alcanzar este mensaje supone una búsqueda individual, escuchando los silencios de las obras para recibir un eco personal de significados para unir las relaciones que se establecen entre los distintos elementos que las conforman, en obras como Sombras de Luz (Fig. 4), con matices materiales e inmateriales, en Imagen Real, Imagen Virtual, visibles e invisibles, o en Memoria enterrada, a través de la fuerza de la metáfora y su poder de evocación poética.

Para sugerir lo imaginario, Alba une forma y materia mediante procedimientos simbólicos, utilizando recursos poéticos como la metáfora, tomando elementos de la realidad, enfrentando formas de la naturaleza con otras creadas por el hombre como mecanismos para sugerir, y llevar al espectador a otro lugar de pensamiento, cuestión que responde esencialmente a la naturaleza del símbolo en la obra de arte. Los títulos de sus obras muestran esa intención de desvelar la clave simbólica y afianzar la literalidad de lo que aparenta ser, siendo anticipos de las preocupaciones metafísicas que encierran: Sombras de Luz, Contenedores de Tiempo, Memoria Enterrada (Fig. 5), Voces, ecos, levedad del tiempo, Proceso, Silencio Orgánico, Tiempo diluido, etc.

La obra no puede eludir su carga poética, ya sea como metáfora, símbolo o alegoría, pudiendo conseguir a la vez que su código sea hermético hasta impedir acceder a la verdad que da sentido a la obra. Alba no está hablando del mundo físico, sino de lo que nos rodea y no se toca y solo se puede intuir: lo trascendente.

El proceso consiste en interpelar al espectador haciéndole partícipe de la misma, para que la someta a su interpretación y la traduzca en experiencia propia. El artista recurre a la simplificación al límite del lenguaje necesario para producir la obra, reduciendo al máximo lo superfluo y renunciando a la representación directa de la realidad estableciendo de modo implícito la diferencia entre ver y mirar. El escultor huye de la realidad directa tratando de desnudar y desvelar cuestiones de otro ámbito, relacionadas con la evocación de lo trascendente. Reacciona por tanto frente a lo di- 
recto en la comunicación y nos enseña el gozo estético desde la interpretación. Para ello se reducen los elementos del lenguaje, en el intento de comunicar una verdad esencial.

Esta reducción del lenguaje a lo mínimo no tiene un fin en sí mismo sino una pretensión de comunicación en la que el lenguaje es sólo una herramienta. Sólo se llega a ello tras una búsqueda o viaje laborioso, intenso y necesario, trabajando en y desde la esencia del pensamiento. El artista refleja dicho ideal reductivo y esencial, aportando a la vez un importante componente didáctico. Sus obras suponen una declaración de intenciones y sólo se revelan para quien sepa traspasar la primera percepción. Las obras de Fernando Alba nos dicen mucho más de lo que nos muestran; son imágenes que estimulan el pensamiento, activan la imagina-

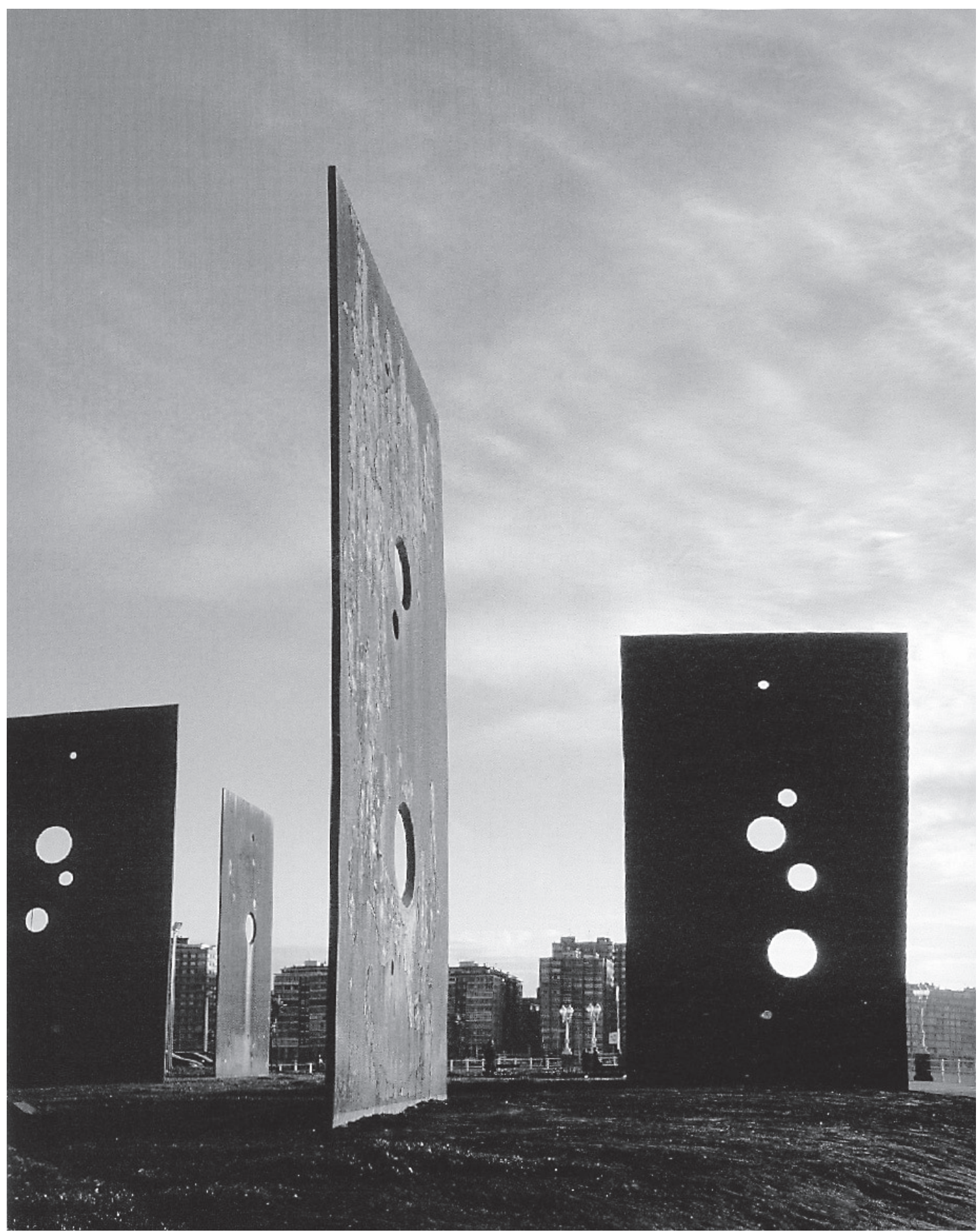

Fig. 4. Fernando Alba. Sombras de luz. Mayán de tierra. Gijón. 1998 


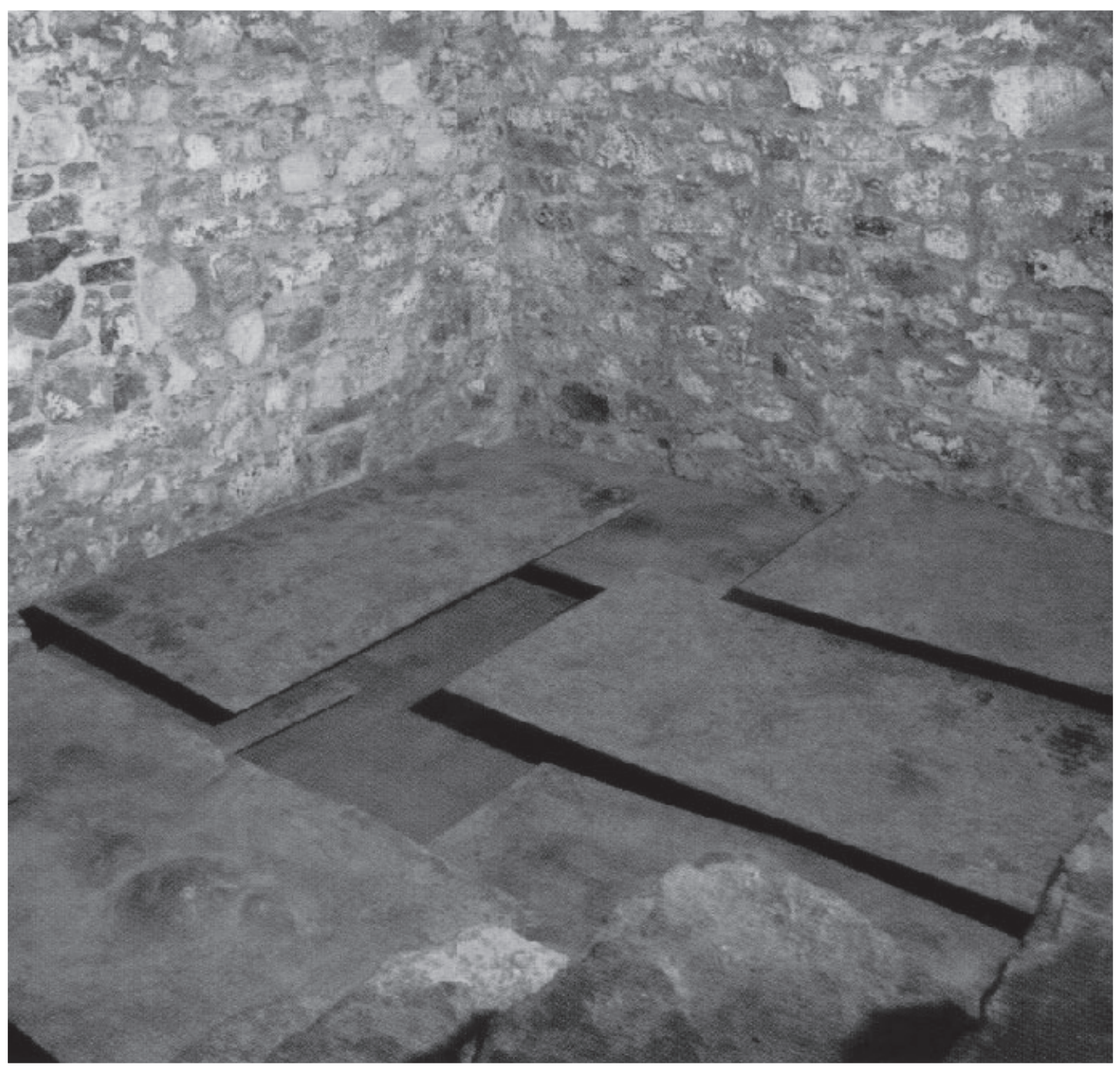

Fig. 5. Fernando Alba. Memoria enterrada. Sótano de la torre Valdés de Salas. 2007

ción, sugieren, insinúan y plantean preguntas, enigmas o suposiciones, incitando a la participación afectiva o emotiva del espectador.

El mensaje no está escondido en lo que no vemos, sino que existe gracias a esta incógnita, que provoca múltiples significados, tantos como miradas. Esta capacidad sugestiva de algunas imágenes, se basa en la sintesis expresiva y a la renuncia de lo explícito apelando a la acción del espectador, mediante la capacidad de sugerir de una manera no impositiva. Cada mirada puede apropiar la obra, hacerla suya, incorporando sus códigos, fantasías e imaginación, multiplicando sus posibilidades con los registros de cada espectador.

Se percibe complejidad, aleatoriedad, y equilibrio construido con un lenguaje con la capacidad de penetrar la parte sensible de nuestra percepción y mostrarnos caminos personales con gran intensidad poética como soporte de una realidad paralela al mundo que le ha tocado vivir, tal y como dijo Jose Ángel Valente "Qué oscuro el borde de la luz donde ya nada reaparece."

Existe un interés creciente en la obra de Fernando Alba hacia lo virtual y por tanto no conocido. Lo irreal vinculado a cierto efecto, hace que el intelecto lo admita como posible. Esa posibilidad de realidad experimentada, es un reflejo de la percepción contemporánea de lo virtual. La obra de Alba no trata de construir una forma sino de transmitir el efecto que produce. Hablaríamos del arte como artificio entre artista y espectador como una de las claves del arte contemporáneo.

\footnotetext{
VALENTE, José Ángel.. El inocente, Joaquín Mortiz, México 1970, p.417
} 
En Sombras de Luz, ¿en qué lugar de la sombra se encuentra la realidad? Lo evidente no tiene la capacidad de seducir, emocionar o lograr una reflexión interesante de la obra. No debemos olvidar que "Platón llamaba imágenes, ante todo, a las sombras" ${ }^{\prime} \mathrm{La}$ esbeltez de las chapas y el corte biselado de los círculos potencian las cualidades de límite de las piezas. Cuando el sol incide sobre ellas, ocurre un cambio conceptual entre la luz del sol y la luz individualizada y atrapada por cada una de las cuatro piezas. La dualidad entre sombra y luz genera la percepción de un vacío en el interior del diedro en sombra, que actúa en este caso como masa, perforada por el haz cilíndrico de luz, que se convierte en vacío.

El límite y la sombra forman un todo, y por tanto son simultáneos. La sombra es un desdoblamiento de la imagen del límite espacial y forma parte de la identidad de la pieza. La sombra se convierte en el límite de otro límite. Existe en la obra un límite estable y otro cambiable, el de la sombra. El contorno del conjunto formado por el límite real y el cambiante forman un diedro que aumenta nuestra percepción del poder de cada chapa y de su conjunto. Pero la sombra no es en realidad un límite, sino una relación homotética o referencia cambiante entre dos límites: la silueta de las piezas y el límite del plano del suelo que las recibe. El poder de la sombra permite simular un escenario en donde se combina información, tensión y emoción, como recurso expresivo de intensidad emocional. Las luces focalizadas suelen remitir a una atmósfera mágica, misteriosa y efectista.

Alba nos está también hablando de un mundo físico, de energías y de luz, que es la materia que hace perceptible el límite que produce la sombra y que fija los límites que percibimos. Sombras de Luz es una especie de cámara oscura que atrapa la luz y la arrastra al interior. Podríamos afirmar que las planchas de acero tienen un haz y un envés. Hay direccionalidad y movimiento. La obra actúa como un instrumento de representación. La mirada, como interpretación de la realidad, da paso a una visión sectorizada que atraviesa la propia obra. Aparece un nuevo espacio óptico o mejor dicho múltiple en donde el observador puede ser el objeto observado.

PLATÓN, La República, Aguilar, Madrid 1959 y 1963 , p. 450. Citado por Victor I, Stoichita, Breve historia de la sombra, Siruela, Madrid, 1999, p. 28
Al percibir la obra a contraluz y no tener color, la sombra propia es negra y oscurece y potencia la percepción de los límites de las planchas. La sombra propia de las piezas es una potenciadora del paisaje: lo enmarca y lo encuadra.

El claroscuro es un recurso que ha sido objeto de estudio a lo largo de la historia del arte, ya que genera un poder mágico que anula partes del campo de visión enfatizando otros. Vermeer es un claro ejemplo de habilidad en el manejo de luces y sombras generando una atmósfera especial, imprimiendo a la obra un carácter escenográfico y fotográfico del instante, haciendo vibrar el momento en el que el tiempo interviene. Velázquez fue un maestro utilizando los negros y Zurbarán los planos de sombra para acentuar la espacialidad y vibración de la obra. Por el contrario, la luz arrojada a través de los óculos es una potenciadora del color en el plano horizontal. A su vez, la sombra arrojada de las piezas prolonga su tamaño según la posición solar. Las imágenes de la sombra como proyección pasan a ser un juego en una frágil frontera entre la ilusión y la realidad. La cuestión en Sombras de Luz es donde percibimos mayor información, si en la propia obra o en la imagen de su sombra arrojada. Y precisamente la conexión entre estos dos entes, figura y sombra, está en los cilindros de luz que los unen como si de unos hilos virtuales se tratase. Además, la sombra delimita un diedro y nos ayuda a recibir una información añadida del espacio donde nos encontramos. La sombra tiene la capacidad de definir perceptivamente el espacio, es decir, de simularlo. El espacio también está en la sombra. Al convertirse los círculos en cilindros de luz proyectados sobre la sombra en la imagen especular de cada pieza, las sombras adquieren el papel de reflejo-espejo deformado de la realidad, pasando a ser una imagen virtual de las planchas de acero. Los círculos de chapa se trasladan al pavimento del paseo, prolongando y creando relaciones espaciales más allá de la propia pieza.

La obra, leída en esta clave, remite a concavidad, virtualidad, misterio, diedro, tiempo, simetría, ficción, desdoblamiento, esquizofrenia, multiplicación, repetición, distorsión y complejidad.

Los círculos horadados, convertidos en haces de luz, nos aparecen como soles, estrellas, planetas, cometas, y en definitiva, nos transportan a una percepción del cosmos y por tanto 
a una referencia de infinitud. Alba siempre se refiere a la obra como un viaje. Los círculos se convierten en negativo, delimitan y acotan espacialmente, estableciendo relaciones con las referencias luminosas y conforman una topografía negativa del espacio. Se trata de un discurso de señales que reflejan un nuevo espacio cuyas visiones pueden enmarcar el fondo de la ciudad.

Eugenio Trías describió las sombras como el lugar donde el intelecto puede conseguir su madurez y solvencia ${ }^{9}$, relacionando con el discurso que establece la razón, con lo irracional. Las sombras tienen una capacidad emotiva o seductora de igual capacidad a la luz. Alba ha manejado la capacidad de densidad, dramatismo y poesía de las sombras utilizando su carga simbólica expresiva. Como resalto Tanizaki, se logra crear belleza haciendo nacer sombras en lugares en sí mismos insignificantes. ${ }^{10}$

En Occidente, el más poderoso aliado de la belleza fue siempre la luz. En la estética tradicional japonesa lo esencial está en captar el enigma de la sombra. Lo bello no es una sustancia en sí sino un juego de claroscuros producido por la yuxtaposición de las diferentes sustancias que va formando el juego sutil de las modulaciones de la sombra. Lo mismo que una piedra fosforescente en la oscuridad pierde toda su fascinante sensación de joya preciosa si fuera expuesta a plena luz, la belleza pierde toda su existencia si se suprimen los efectos de la sombra. Alba ha sabido colocar 4 piezas en la bahía de Gijón a modo de captadores para que cada espectador sepa leer en la obra, la belleza que en ella habita, según una escultura interactiva, como estructura abierta de significados.

Sombras de Luz ha tenido una importancia significativa en la obra de Fernando Alba, manejando la sombra como uno de los recursos que el escultor utiliza como elemento definidor de espacios y potenciador de conceptos en sus obras. En Proceso, en Salas, la utiliza encerrada en el espacio de las dos placas de acero deformadas. En Memoria enterrada, como espacio de relación entre los elementos. En Devenir, como energía que hace flotar la obra del plano horizontal. En Silencio Orgánico, en el perímetro de la pieza, como alusión al espacio magmático que subyace bajo el suelo. En Espacios de Interrogación y en Octubre como misterio oculto.

El sobrecogimiento que puede suscitar la obra definido como "una sensación que invade al espectador en presencia de un objeto que le conmueve poderosamente y a veces puede incitar a una exploración posterior" ${ }^{11}$ se produce como un acto experimental del perceptor, como una invitación a volver a presenciar el objeto, o recorrerlo en la búsqueda de nuevas interpretaciones. Esta es la invitación permanente de Fernando Alba.
TRIAS, Eugenio, La razón fronteriza, Editorial Destino, Madrid, 1999

10 TANIZAKI, Junichiro, El elogio de la sombra, Ediciones Siruela, Biblioteca de Ensayo, Madrid, 1994, p. 50 
